\title{
IMPACTO DA ISO 9001:2000 NOS ASPECTOS GERENCIAIS DOS ESCRITÓRIOS DE ARQUITETURA: ESTUDOS DE CASO EM EMPRESAS CERTIFICADAS
}

\author{
Clarice S. C. FERREIRA \\ Arquiteta, Mestre em Arquitetura pela Universidade \\ Federal do Rio de Janeiro \\ claricesfair@superig.com.br \\ Mônica S. SALGADO \\ D.Sc, Professor Associado - Programa de Pós- \\ graduação em Arquitetura - Universidade Federal do \\ Rio de Janeiro \\ monicassalgado@ufrj.br
}

\begin{abstract}
RESUMO
A busca pela melhoria da qualidade nas empresas construtoras teve início com a implantação de sistemas de gestão da qualidade. Recentemente tem se observado também o interesse por parte de alguns projetistas na organização dos seus sistemas de gestão, tomando por base os requisitos da norma ISO 9001/2000. Os escritórios de arquitetura foram os últimos a buscar este caminho, apesar de ser reconhecida a importância do projeto para a redução dos desperdícios e racionalização da construção. Um dos motivos que leva ao descrédito por parte de alguns arquitetos em relação aos benefícios gerados pela implantação de um sistema de gestão da qualidade é o fato desse sistema não garantir a qualidade do projeto em si, mas da gestão do processo de desenvolvimento do projeto. Com o objetivo de identificar os impactos provocados pela implantação de um sistema de gestão da qualidade nos moldes da norma ISO 9001/2000, realizou-se estudos de caso nos escritórios de arquitetura certificados. Os resultados indicam certa mudança de postura a partir das exigências da norma, com destaque para a maior preocupação, por parte dos projetistas, com a gestão da informação e comunicação.
\end{abstract}

Palavras-chave: Escritórios de Arquitetura, Sistema de Gestão da Qualidade, Gestão da Informação.

\section{ABSTRACT}

The search for quality improvements in construction companies has begun with the implementation of quality management systems. Recently some designers have showed interest on the organization of their management systems based on the ISO 9001/2000 norm. The architecture bureaus were the last to seek this path even despite of the recognized importance of the project when it comes about reducing waste and rationalizing the construction. One of the reasons that lead some architects in order not to give the real importance to the benefits that come from the implementation of quality management system is the fact that this system does not guarantee the quality of the project itself, but rather the management of the process of developing the project. With the purpose of identifying the impacts caused by the implementation of a quality management system as described by the ISO 9001/2000 norm, a study of case was undertaken with certified architecture design offices. The results indicate some changes on the designer's attitude due to the requirements of the norm, with emphasis at the biggest concerns that are the information and communication management.

Key words: Architecture Bureaus, Company Management, Quality Management System, Information Management. 


\section{INTRODUÇÃO}

A aplicação de sistemas de gestão da qualidade baseados nas normas NBR ISO 9000 já não é mais novidade na indústria da construção civil e são vários os trabalhos que estudam as vantagens e desvantagens da aplicação dessa norma para o setor.

O setor de projetos foi o último a buscar a compreensão e incorporação dos requisitos da norma às suas práticas de trabalho. Vários estudos já foram realizados visando a identificar quais modificações foram realizadas nos escritórios ao incorporarem os procedimentos necessários ao cumprimento dos requisitos estabelecidos pela norma. Entretanto, verifica-se que poucos trabalhos tiveram como foco principal o sistema gerencial adotado pelas empresas de projeto.

Um sistema de gestão é tudo o que uma organização faz para gerenciar seus processos ou atividades, ou seja, a forma do como fazer. Porém, um sistema de gestão exige que esse conhecimento, que na maioria das vezes está na "cabeça das pessoas", seja documentado. Um sistema documentado contribui para assegurar que as pessoas na organização não estejam apenas "fazendo o seu trabalho", mas que estejam fazendo o trabalho do jeito que a organização deseja que o trabalho seja feito (SALGADO, 2006).

É importante lembrar que, apesar de o processo de produção de projeto ser o subsistema mais importante de uma empresa de projeto, outros subsistemas - tais como recursos humanos, marketing, finanças, sistema de informações, entre outros - também são essenciais para garantir a sobrevivência do negócio. Nesse sentido, Oliveira (2005) ressalta que não é possível alcançar todos os potenciais benefícios no processo do projeto se o sistema de gestão das empresas responsáveis pela sua produção for deixado em segundo plano.

O CTE (2001) confirma essa posição, acrescentando que somente a elaboração de procedimentos sobre o desenvolvimento do projeto não compõem um SGQ uma vez que a empresa de projeto não se constitui somente dos processos de desenvolvimento técnico dos projetos. A empresa de projeto deve, também, desenvolver processos que dêem suporte à sua estratégia e à garantia da qualidade de seus produtos. Considerando as especificidades dos escritórios de projeto, seria importante que este desenvolvesse procedimentos que estivessem relacionados à gestão global da empresa.

Assim, considerando que o SGQ numa empresa de projeto deve ir além da gestão do projeto em si, este trabalho teve como objetivo identificar o impacto da implantação de um SGQ, baseado na Norma ISO 9001:2000, sobre os aspectos gerenciais dos escritórios de arquitetura. Entende-se que essa visão pode auxiliar aos escritórios que pretendem adequar suas práticas de trabalho aos requisitos da norma ISO 9001/2000. 


\section{ASPECTOS LIGADOS À GESTÃO E ORGANIZAÇÃO DE ESCRITÓRIOS DE ARQUITETURA}

Para que todos os processos de uma empresa ocorram de maneira eficaz, é necessário o estabelecimento de uma estrutura organizacional que sirva de base a todos os seus procedimentos administrativos e técnicos.

A principal função da estrutura organizacional é auxiliar no alcance dos objetivos organizacionais. Para Oliveira (1994), quando a estrutura organizacional é estabelecida de forma adequada, ela propicia à empresa: identificação das tarefas necessárias; organização das funções e responsabilidades; informações, recursos e feedback aos empregados; medidas de desempenho compatíveis com os objetivos; e condições motivadoras.

Toda empresa possui dois tipos de estrutura: a formal e a informal. A informal não é planejada e surge naturalmente da interação social dos membros de uma empresa. A estrutura formal é aquela deliberadamente planejada e formalmente representada, em alguns aspectos, pelo organograma. A vantagem da formalização é que ela representa a expressão dos desejos dos dirigentes no sentido de balizar o funcionamento da organização, enquanto que a informalização representa a expressão dos desejos dos membros da organização localizados em grupos informais (PINTO, 2002).

Ao se implantar um SGQ, é apropriado definir a estrutura organizacional da empresa, pois ela contribui para a implantação do sistema, através da alocação de pessoas e de recursos para as tarefas que precisam ser feitas e ao proporcionar mecanismos para a coordenação dessas tarefas.

A gestão de um escritório de arquitetura envolve diversos aspectos, entre eles está o planejamento estratégico, que pode ser definido como "o processo de interferir na realidade, com o propósito de passar de uma situação conhecida para outra situação desejada, dentro de um intervalo definido de tempo"(MAXIMINIANO, 1995, p. 197).

O planejamento estratégico envolve, também, a definição de objetivos e metas da empresa e a criação de um plano de ação. O plano de ação define prazos e meios para alcançar as metas estipuladas.

Outro ponto importante é a definição de meios de controle, que visam a acompanhar o plano de ação, verificando o cumprimento ou não deste. Assim, é possível a tomada de ações corretivas e, se necessário, o re-alinhamento das metas e da estratégia empresarial adotadas.

Para Souza (2004), para que as metas de uma empresa sejam consistentes, abrangentes e sinérgicas devem envolver vários aspectos que abarcam a organização, tais como:

- perspectivas financeiras: são as metas relacionadas à satisfação dos acionistas da empresa. Podem estar ligadas a aspectos como: faturamento anual pretendido pela empresa, despesas fixas de escritório a serem alcançadas, etc.

- perspectivas dos clientes e do mercado: São metas relacionadas à inserção da empresa no mercado e à satisfação dos clientes da empresa. Podem estar ligadas a aspectos como: número de projetos contatados no ano, grau de satisfação dos clientes com os serviços oferecidos pela empresa. 
- perspectivas dos processos internos: São metas relacionadas ao desenvolvimento organizacional e à busca da excelência nos processos internos da empresa e podem estar ligadas aos seguintes aspectos: implantação de sistema informatizado de gestão empresarial, certificação da empresa em gestão da qualidade ou gestão ambiental, etc.

- perspectiva do crescimento e do aprendizado: são metas relacionadas à criação de novas competências organizacionais, envolvendo o crescimento e o aprendizado da empresa e de seus profissionais. Podem estar ligadas aos seguintes aspectos: capacitação da empresa para atuar em novos mercados, programa de capacitação profissional dos funcionários, etc.

A definição da estratégia da empresa implica: selecionar os segmentos de atuação desejados pela empresa, identificando demandas existentes nesses segmentos e seus competidores e estabelecer qual a estratégia de competição que será adotada pela empresa.

Ressalte-se que o planejamento estratégico não é formalmente realizado nos escritórios de arquitetura, cuja estratégia é normalmente traçada intuitivamente pelos seus diretores e, exatamente por isso, não são monitoradas.

Naturalmente a definição da estratégia da empresa deve ser acompanhada por um trabalho de marketing, que pode ser entendido como a atividade humana dirigida para a busca da satisfação das necessidades e dos desejos dos consumidores, através dos processos de troca. Neste caso, as trocas referem-se à compra ou venda de produtos e/ou serviços (KOTLER, 1980).

Um sistema de marketing geralmente é composto dos seguintes aspectos: preço, praça (distribuição), produto e promoção (divulgação, propaganda), os 4Ps. Para Kotler (1999), essa é uma ferramenta muito utilizada na área do marketing, pois serve para orientar o seu planejamento. Servem como diretrizes, do ponto de vista do vendedor, a serem delineadas para que determinado produto seja colocado no mercado e divulgado.

O primeiro $\mathrm{P}$, produto, identifica o que está sendo vendido, pode significar um produto pronto (é a imagem com que chegará no mercado), como também incluir serviços que o acompanham ou mesmo ser um serviço. No Preço é considerado o valor que produto será disponibilizado (valor bruto mais encargos e lucros). Praça está relacionada com o local e o público para quem o produto será comercializado e Promoção, a propaganda que será realizada para informar e convencer o mercado de que 'tal produto' é o melhor e mostrar o maior número de benefícios inerentes a ele.

Para Kotler e Bloom (1998, p.20), uma maneira eficaz para um escritório de projetos de arquitetura promover-se é por meio de cobertura jornalística sobre seu trabalho, da obtenção de prêmios e da prática de comunicar constantemente aos seus clientes sobre seus hábitos positivos, como realizar projeto dentro do prazo e do orçamento.

Para Padilha (2006, p. 24-38), o projeto de arquitetura é um serviço de consumo restrito, não adquirido por muitas pessoas muitas vezes na vida, excetuando projetistas e construtores/ incorporadores. Não é um produto fácil para ser compreendido pelo cliente, pois para estes o projeto é entendido como um meio, muitas vezes compulsório, para se chegar a este produto (a edificação). Assim, 
vender projetos de arquitetura requer, além dos conhecimentos técnicos, habilidades e conhecimentos de gerenciamento e de mercado, capacidade de lidar com os clientes.

A definição do produto de uma organização faz parte do composto de marketing e é fundamental para o sucesso da empresa. A definição do produto deve partir do conjunto de decisões que a direção toma sobre o que vai ser disponibilizado no mercado, e está relacionado com a estratégia da empresa. Assim, numa empresa de projetos de arquitetura, a administração do escritório (direção) deve definir claramente uma linha de produtos (política de produto). Uma empresa de projeto deve escolher seu nicho de mercado e trabalhar predominantemente para ele, por exemplo: projetos de hospitais, projetos residenciais, comerciais etc.

O profissional de arquitetura geralmente oferece uma gama de produtos muito variados, é um "faz tudo", o que dificulta que o profissional fixe a sua imagem no mercado. Essa postura pode ser justificada pela inconstância da demanda por serviços, que está diretamente ligada à conjuntura econômica e setorial. Porém, apesar dessa adversidade, é possível que um escritório de arquitetura selecione um nicho de mercado e trabalhe predominantemente neste.

Outro aspecto fundamental para a gestão das empresas de projeto é o estabelecimento de um adequado sistemas de informações. Estes sistemas transformam dados e conhecimentos em informações para poder responder a uma variada gama de possibilidades.

A principal utilização de um sistema de informação é no auxílio à tomada de decisão. Para isso, o sistema deve ser abrangente, produzir todas as informações necessárias em todos os níveis da organização.

Um adequado sistema de informações pretende facilitar o trabalho das pessoas, a aprendizagem e a redução de conflitos e, principalmente, reduzir as incertezas das decisões administrativas. As informações auxiliam o administrador a calcular e minimizar os riscos de suas decisões. Ou seja, os fluxos de informações estão diretamente relacionados à tomada de decisão.

Para Gray e Al-Bizri (2004), o processo do projeto é um processo da transformação da informação na ação. Cada decisão do projeto é feita em consequiência de uma interação entre o conhecimento do projetista e a informação que recebeu sobre o problema específico de outros projetistas no mesmo domínio, de outros domínios envolvidos no processo do projeto, do cliente, de autoridades regulamentadoras, de grupos de usuários do edifício, etc. Um projetista necessita de informação para selecionar, entre várias ações alternativas, os resultados que não podem ser distintos entre si sem a informação, daí a importância do sistema de informações para o arquiteto.

Para que o sistema de informações funcione adequadamente, é importante que a empresa estabeleça critérios para geração e controle e registro de informações. Para Oliveira (2005) a perfeita gestão das informações, tanto físicas quanto eletrônicas ou verbais, são de fundamental importância para o desempenho das empresas de projeto.

A Tecnologia da Informação (TI) é uma parte do sistema de informação. Dá-se esta denominação às tecnologias usadas para introduzir, armazenar, processar e 
distribuir informações por meios eletrônicos. A TI compreende eletrônica, automação, computação (hardware e software) e telecomunicações. Para Nascimento e Santos (2003), a TI tem grande importância nas empresas de projeto, pois essas empresas lidam fundamentalmente com informação e existe uma intensa utilização do computador ao longo de seus processos. Nessas empresas, os insumos podem vir sob forma digital (documentos, eletrônicos, e-mail, videoconferência etc.), bem como os produtos que geram (arquivos CAD, documentos eletrônicos) podem ser entregues aos clientes. Seus funcionários podem trabalhar remotamente e a empresa pode ser contratada por clientes de todo o mundo.

Atualmente, além de utilizarem a TI para elaborar documentos eletrônicos, através de programas de edição de texto, planilhas eletrônicas e programas CAD, as empresas de projeto podem usar a TI como ferramenta de auxílio à coordenação de projetos, por exemplo através do uso de sites colaborativos, que representa um grande avanço na comunicação entre os vários envolvidos no processo de projeto de edificação, possibilitando uma maior rapidez no fluxo de informações.

Mas a tecnologia de informação somente funcionará se a equipe de profissionais que atua na empresa tiver recebido adequado treinamento. Dessa forma, pode-se inferir que entre os subsistemas mais importantes de qualquer empresa encontra-se a gestão dos recursos humanos.

A gestão de recursos humanos de uma empresa assegura a existência de pessoas adequadas e motivadas para exercerem suas funções. Ela deve comunicar de forma clara e completa os princípios técnicos e administrativos estabelecidos pela organização, gerando a elaboração de normas, procedimentos, padrões, programas e atividades. Processos como os de contratação e de treinamento devem fazer parte da gestão estratégica do negócio, pois quando se tem como objetivo fazer o melhor uso de recursos humanos, deve-se pensar em como "colocar a pessoa certa, no lugar certo, por um tempo certo".

As empresas devem ter uma definição clara das características dos ocupantes dos cargos, definir as competências necessárias do profissional a atuar na organização, criar o perfil profissional que será utilizado no recrutamento e seleção, além de estabelecer quais tipos de treinamento podem ser adequados.

A atividade de projetar possui um alto componente intelectual inerente ao serviço. A seleção dos profissionais que vão atuar num escritório de arquitetura deve levar em conta o perfil que se deseja para a empresa e quais as competências e habilidades requeridas para as funções estabelecidas. Cabe à alta administração definir os papéis estratégicos e operacionais e estabelecer a estratégia de atuação a ser adotada pela empresa, orientando os processos de contratação dos profissionais.

Ressalte-se, ainda, que todo o trabalho de gestão do processo do projeto e organização dos escritórios de arquitetura deve ser acompanhado por um eficiente sistema de gestão financeira. Para uma empresa se tornar bem sucedida, ela precisa ganhar o suficiente para cobrir seus gastos fixos e os custos variáveis, além da sua margem de lucro. Para isso, é importante a empresa saber estabelecer o valor adequado dos seus produtos ou serviços. 
Em muitas empresas de arquitetura, o preço é determinado de maneira empírica, assim como o gerenciamento dos custos de produção. A formação dos preços de projeto, normalmente, é feita através de tabelas que estabelecem índices por área, baseados no CUB (Custo Unitário Básico). Porém, para Scheer; e Cararo (2004), os honorários baseados nestas tabelas não indicam a forma como as atividades envolvidas no desenvolvimento do projeto utilizam os recursos, ou seja, não se tem noção dos custos diretos (os custos de fabricação e venda do produto ou serviço) e indiretos (aluguel, luz, água) associados a estas atividades, e também das despesas geradas pelo serviço.

Segundo estes mesmos autores, o melhor método de formação de preços em empresas de arquitetura é o método baseado em custos pois proporcionam um melhor planejamento dos trabalhos facilitando o controle do orçamento previsto e do desempenho da equipe, a identificação das necessidades de recursos humanos e a visualização de informações sobre os custos, os quais podem assegurar a negociação dos honorários e as modificações de contrato.

A gestão financeira, assim como tudo o que ocorre na organização, deve ser estabelecida em função de um horizonte estratégico. Perder esta perspectiva e fazer cada atividade como um fim em si mesma, acarreta uma distorção de objetivos e uma perda de eficiência e eficácia.

Assim, nota-se que, para gerir uma empresa de arquitetura, o arquiteto, além de ter a formação técnica, deve ser capaz de gerenciar recursos de diversas ordens: pessoas, equipamentos, capitais, conhecimento e serviços que geram projetos e consultorias. E para que o processo de projeto ocorra de maneira satisfatória, é necessário que o ambiente organizacional onde ele é desenvolvido (empresa de projeto) proporcione condições favoráveis para sua operacionalização, levando-se em conta todos os aspectos relacionados.

\section{ESTUDO DE CASO}

Com o objetivo de verificar de que forma a implantação de um Sistema de Gestão da Qualidade afeta o dia-a-dia dos escritórios de arquitetura, optou-se pela realização de um estudo de caso nas empresas que tivessem a certificação pela norma ISO 9001/2000.

O estudo de caso é definido por YIN (2005, p.32) como "uma investigação empírica que investiga um fenômeno contemporâneo dentro do seu contexto real de vida, especialmente quando as fronteiras entre o fenômeno e o contexto não são absolutamente evidentes". Assim, essa metodologia se aplica a esta pesquisa por analisar um fenômeno atual - a implantação do SGQ em escritórios de arquitetura e por se tratar de uma pesquisa na qual as condições contextuais são altamente pertinentes ao fenômeno estudado.

Optou-se pelo estudo de casos em mais de um escritório de arquitetura, com o objetivo de comparar diferentes resultados. Na coleta de dados nessas empresas foram utilizadas múltiplas fontes de evidências como questionários, entrevistas e a análise dos documentos das empresas estudadas.

O critério para a seleção dos escritórios que participaram dos estudos de caso foi o fato de estarem certificados pela norma ISO 9001:2000. Para selecionar essas empresas, fez-se uma pesquisa no catálogo de certificados emitidos do CB-25 da 
ABNT. No momento da consulta (março de 2006), foram encontradas dezesseis empresas de arquitetura certificadas (Gráfico 1), sendo que oito dessas estavam localizada no Estado de São Paulo. Por essa razão decidiu-se concentrar a realização da pesquisa nesse Estado.

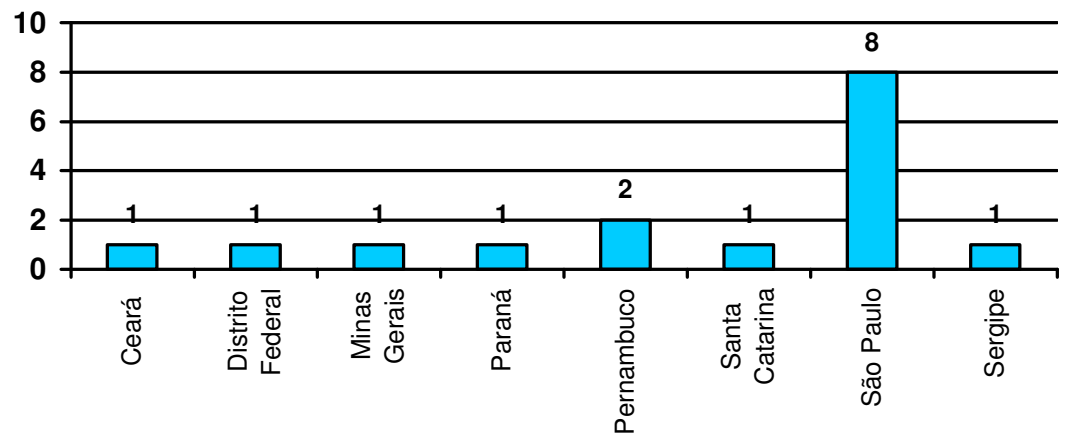

Gráfico 1: Número de escritórios de arquitetura certificados pela ISO 9001:2000 em março de 2006

A partir dos dados obtidos no catálogo do CB-25, estabeleceu-se o contato telefônico com essas oito empresas convidando-as a participar da pesquisa. Das oito empresas contactadas, apenas quatro aceitaram o convite (Tabela 1).

Na caracterização das empresas estudadas, para estabelecer o porte das mesmas foi usado o número de funcionários, como indicado pelo SEBRAE. De acordo com esse, uma empresa na área de comércio e serviços pode ser classificada como: microempresa se tiver até 09 pessoas ocupadas; pequena empresa se tiver de 10 a 49 pessoas ocupadas; média empresa se tiver de 50 a 99 pessoas ocupadas; e grande empresa se tiver acima de 99 pessoas ocupadas.

Confrontando essa classificação com os dados publicados pelo PSQ (1997), que relata que o segmento de projetos de engenharia e de projetos de arquitetura é formado por empresas que empregam até quinze funcionários, conclui-se que provavelmente a maioria dos escritórios de arquitetura do país seria classificado como micro ou pequena empresa. Portanto, pode-se inferir que a classificação do SEBRAE não é compatível com a escala do mercado de projetos de arquitetura, no qual uma empresa com mais de 20 funcionários é normalmente considerada como uma empresa de grande porte.

Entende-se que seria interessante adotar-se uma classificação de porte específica (sem fins políticos, legislativos ou financeiros) para empresas de projeto de arquitetura, que representasse de forma mais verdadeira a realidade do setor. Adotando-se esse princípio por definição, as empresas A, B e C poderiam ser consideras empresas de grande porte. Na Tabela 1, entretanto, apresenta-se a classificação conforme determina o SEBRAE. 


\begin{tabular}{|c|c|c|c|c|c|}
\hline Fundação & $\begin{array}{c}\text { Tempo de } \\
\text { Atuação }\end{array}$ & Nicho de Mercado & $\begin{array}{c}\mathbf{N}^{\circ} \text { Funcio- } \\
\text { nários }\end{array}$ & $\begin{array}{c}\text { Porte Empresa } \\
\text { (SEBRAE) }\end{array}$ \\
\hline $\begin{array}{c}\text { Empresa } \\
\text { A }\end{array}$ & 1988 & 18 anos & $\begin{array}{c}\text { Projetos comerciais, } \\
\text { hoteleiro e residencial }\end{array}$ & 25 & $\begin{array}{c}\text { Pequena } \\
\text { Empresa }\end{array}$ \\
\hline $\begin{array}{c}\text { Empresa } \\
\text { Empresa } \\
\text { C }\end{array}$ & 1962 & 44 anos & $\begin{array}{c}\text { Projetos de edifícios } \\
\text { residenciais, comerciais e } \\
\text { de serviços }\end{array}$ & 25 & $\begin{array}{c}\text { Pequena } \\
\text { Empresa }\end{array}$ \\
\hline Empresa & 1984 & $\begin{array}{c}\text { Projetos de edifícios } \\
\text { residenciais, comerciais e } \\
\text { de serviços, projetos para } \\
\text { galpões industriais e } \\
\text { projetos de interiores de } \\
\text { escritórios }\end{array}$ & 9 & Micro empresa \\
\hline 1993 & 13 anos & $\begin{array}{c}\text { Projeto de vedações; } \\
\text { compatibilização e } \\
\text { coordenação de projetos;e } \\
\text { desenvolvimento de } \\
\text { projetos executivos de } \\
\text { arquitetura }\end{array}$ & 30 & $\begin{array}{c}\text { Pequena } \\
\text { Empresa }\end{array}$ \\
\hline
\end{tabular}

Tabela 1: Resumo das principais características das empresas estudadas.

\subsection{Resultados da Empresa A}

A empresa A se interessou em implantar o sistema de gestão da qualidade procurando sua modernização. A primeira certificação da empresa ocorreu no ano de 2000, ainda pela versão anterior da norma (1994). Em 2004, o SGQ foi recertificado de acordo com os novos requisitos da versão 2000 da norma.

Para implantar o SGQ, a empresa teve auxílio de um consultor externo e a implantação durou cerca de um ano. Durante o processo de implantação, houve certa resistência da equipe e dos próprios diretores, pois houve uma mudança cultural, ou seja, a forma de trabalhar na empresa mudou muito por conta da implantação do SGQ.

A empresa A teve dificuldades de se adaptar à versão 1994 da norma De acordo com o representante da empresa, o processo era muito "engessado" e tinha que atender os requisitos que, de acordo com a sua visão, "não faziam sentido". Ele menciona o registro de informações desnecessárias, que não agregavam valor à qualidade do desenvolvimento dos projetos. Porém, com a nova versão da norma e através do processo de melhoria contínua, a empresa foi se adaptando melhor as exigências do SGQ.

A empresa não considera que o SGQ tenha influência sobre o seu processo criativo,. Para ela o sistema influencia apenas o processo de produção do projeto. Como principais mudanças ocorridas na empresa, destacam-se: a melhoria do sistema de informações, a melhoria do treinamento de funcionários e maior controle sobre a produção da empresa.

Para incentivar os funcionários a se envolverem com o SGQ, a empresa atribuiu uma responsabilidade para cada profissional perante o sistema e eles foram incentivados a fazer sugestões dentro do seu campo de trabalho. 
"O escritório passou a ter conhecimento dele mesmo, do que ele está fazendo, de como ele está fazendo, de que forma, se está sendo rentável ou não. Muda muito a visão dos diretores sobre a empresa. A empresa fica transparente."

(Coordenador de projetos/ Representante da Direção entrevista realizada em 04/2006)

Antes da implantação do SGQ, a empresa A não tinha uma estrutura organizacional definida. Durante a implantação, definiu-se o organograma da empresa.

Antes da implantação do SGQ, a empresa não realizava um planejamento estratégico e seus rumos eram decididos de forma empírica. Porém com a implantação do SGQ, a empresa passou a cumprir o item da norma referente ao estabelecimento de objetivos da qualidade, pelo qual a alta direção deve planejar o SGQ, passando, assim, a realizar um dos elementos do planejamento estratégico: o estabelecimento formal de metas de médio e longo prazo. A empresa passou a estabelecer metas em relação a: expectativas do cliente, resultados do produto (cumprimentos de prazos de projeto, uso de novas tecnologias e uso do projeto em obra), redução de custos, racionalização da produção, treinamento dos funcionários, lucro do negócio e fortalecimento da imagem da empresa no mercado. A empresa destaca que passou a programar-se melhor, tendo que definir constantemente metas a serem atingidas, assim como reavaliar essas metas periodicamente.

Com relação à estratégia de marketing, durante a implantação do SGQ, a empresa definiu que gostaria de mudar sua imagem no mercado, que estava muito ligada ao projeto de habitação popular. Definiu-se que ela deveria ter mais participação no mercado de residencial de médio e alto padrão. Esse objetivo foi incluído em suas metas e foi contratado um assessor de marketing para modificar e fortalecer a imagem da empresa. Para se promover, a empresa procura em estar sempre em evidência na mídia através da publicação de seus trabalhos.

Quanto à área de atuação (Praça), a empresa atua majoritariamente em São Paulo, apesar de fazer eventualmente projetos em outros locais do país. Essa escolha não é intencional já que o volume de trabalho conseguido no Estado é suficiente para ocupar toda sua capacidade de trabalho.

Já com relação ao estabelecimento de preço para os projetos, a empresa A afirma que nunca usou nenhuma tabela de classe. Para formular o preço dos projetos elaborados, ela se baseia no seu histórico de preços cobrados por projeto e nos preços praticados pelo mercado. A empresa não cobra adicional para visitar as obras, pois esse serviço já é incluído no escopo do trabalho.

Em relação aos recursos humanos, depois da implantação do SGQ, a empresa passou a investir mais nos seus funcionários. Todo ano é feito um planejamento de treinamentos no qual se estabelece que tipo de treinamento cada profissional necessita e, dependendo do caso, a empresa paga parte dos custos ou todos os custos com esses treinamentos. Além disso, passou-se a dar treinamento para os novos funcionários, para que aprendam os procedimentos e rotinas da empresa. 
Quanto à seleção de funcionários, antes da implantação do SGQ, era feita apenas com base em indicações. Por exigência da norma ISO 9001, criou-se um manual de cargos, no qual são descritas as habilidades necessárias de cada função. Assim, a seleção passou a ser feita com base nos requisitos estabelecido nesse manual.

A empresa possui projetistas que atuam como parceiros no desenvolvimento de etapas do projeto de arquitetura. Esses projetistas, conforme uma determinação da norma, passaram a ser avaliados e qualificados. Os projetistas parceiros considerados qualificados são mantidos em um cadastro de fornecedores controlado, que tem critérios tanto para a aceitação de um novo fornecedor, como para sua manutenção ou exclusão do cadastro.

Para a empresa A, a principal mudança na organização com a implantação do sistema de gestão da qualidade refere-se ao sistema de informação. Abaixo o depoimento do entrevistado quando perguntado sobre as principais transformações na empresa com a implementação do SGQ.

"Primeiro o controle sobre a informação. Independente de que tipo, de que setor, de grau de importância sobre o projeto é fundamental. Você tem domínio sobre o que você está elaborando e você tem controle total sobre todos os aspectos. Foi muito importante para a elaboração do projeto e para o escritório ter conhecimento dele mesmo, do que ele está fazendo, de como ele está fazendo e de que forma".

(Coordenador de projetos/ Representante da Direção entrevista realizada em 04/2006)

De acordo com a empresa A, passou-se a ter maior controle sobre as informações de projeto, aumentando-se a qualidade e a confiabilidade das informações liberadas tanto para o cliente contratante como para os projetistas de especialidade. Como a empresa, geralmente, também trabalha coordenando os demais projetos de especialidades, a precisão das informações é muito importante. Com a implantação do SGQ, passou-se a tomar mais cuidado em registrar todas as informações e decisões de um projeto. Por exemplo, a cada projeto abre-se uma pasta onde vão ser armazenadas todas as informações referentes a ele (faxs, e-mails, documentos, etc). Quando durante uma conversa por telefone alguma decisão é tomada ou alguma informação é repassada, estas também são registradas de maneira formal, num documento que é armazenado na pasta referente ao projeto. Desse modo, mantém-se um histórico que pode ser consultado para esclarecimento de qualquer dúvida, reduzindo os problemas de comunicação que geram incompatibilidades entre projetos.

Criou-se uma identificação padronizada para os documentos tanto em formato físico como eletrônico, assegurando a rastrebilidade dos mesmos. Também foram criados procedimentos referentes a alterações de projetos, ao manuseio e ao armazenamento de documentos. Para recuperação de arquivos eletrônicos, foram criados os procedimentos de backup (cópias) diários, semanais e mensais. 
A empresa já utilizou ambientes colaborativos para troca informações. O uso dessa ferramenta se dá quando o cliente contratante fornece a mesma. Na sua ausência, a troca de informações se dá por e-mail.

Para cumprir outra exigência da norma ISO 9001, a empresa criou um instrumento específico para avaliação dos seus projetos junto aos clientes contratantes e construtores. Essa avaliação é feita através de formulários.

Em relação às obras, depois da implantação do SGQ, a empresa considera que sua postura mudou muito, pois anteriormente ela tinha pouco contato com as empresas que executavam seus projetos durante as obras. Atualmente, a empresa procura visitar as obras para conhecer as opiniões da construtora sobre a qualidade e a quantidade das informações apresentadas nos detalhes e nas plantas. Todas as informações coletadas são analisadas e usadas para re-alimentar o projeto dentro da empresa. Porém a empresa não faz avaliação do seu projeto junto aos usuários finais do empreendimento

A empresa A não tinha nenhum indicador de produção anterior à implantação do SGQ, o que impossibilita analisar se houve um aumento de produção.

Para a empresa A, a principal dificuldade de manutenção do SGQ é financeira, pois a certificação, auditoria e consultoria são caras e todos os funcionários perdem algumas horas por semestre dedicadas ao SGQ. Apesar disso, a empresa pretende manter a certificação.

\subsection{Resultados da Empresa B}

O interesse da empresa B em iniciar a implantação de seu sistema de gestão da qualidade surgiu devido à solicitação de um cliente que estabeleceu esta condição a todos os seus fornecedores / prestadores de serviços. A implantação do SGQ começou em 1999, com a ajuda de um consultor, e em 2000 a empresa se certificou.

Para a empresa B, a principal dificuldade na implantação do SGQ foi com relação a compatibilização do horário de trabalho dos funcionários do escritório com as atividades necessárias à produção dos documentos para o SGQ. Não houve resistência dos funcionários e todos participaram da implantação dos procedimentos necessários para o atendimento aos requisitos da norma.

Esta também não considera que o SGQ tenha qualquer influência sobre o seu processo criativo. Da mesma forma como foi destacado pela empresa A, para a empresa B o sistema influencia somente o processo de produção do projeto.

Entre as principais mudanças ocorridas na empresa destacam-se a melhoria do sistema de informações e a melhoria do treinamento de seus funcionários. Além disso, antes da implantação do SGQ a empresa B não tinha não tinha uma estrutura organizacional definida e após a implantação (e devido a esta) o organograma da empresa foi formalizado e divulgado para seus funcionários.

Do mesmo modo que a empresa $A$, antes do SGQ, a empresa B não fazia nenhum tipo de planejamento estratégico. Com a implantação do SGQ, a empresa passou a estabelecer várias metas, entre elas: o atendimento aos requisitos (medindo as não conformidades, horas de retrabalho, número de projetos entregues dentro do prazo, projetistas complementares que entregam dentro do prazo); a avaliação do clima organizacional da empresa; a avaliação dos clientes (fichas de avaliação de 
clientes) e o investimento na qualificação profissional dos funcionários (participação em cursos, eventos, etc.). Além disso, através das reuniões de análise crítica, que ocorrem em média a cada três meses, a situação da empresa é analisada e são propostas ações que visam ao atendimento de metas estabelecidas a médio e longo prazo.

Esta empresa nunca se preocupou em estabelecer uma estratégia de marketing. A partir do SGQ a empresa passou a promover sua atuação através da divulgação em revistas especializadas. Além disso, passou a adotar uma nova estratégia para conquistar clientes: a realização de reuniões com clientes em potencial. Quanto ao local de atuação (Praça), a empresa afirma que a escolha de São Paulo se deve ao fato da maioria de seus contatos residir nesta cidade, mas isso não tem impedido a empresa de realizar projetos em outras partes do país.

A empresa B afirmou que também alterou a forma de calcular o preço de projeto, entretanto, segundo depoimento do representante da empresa, esta mudança não ocorreu como conseqüência da implantação do SGQ. Anteriormente, a empresa fazia o cálculo de honorários com base em algumas tabelas e na sensibilidade dos seus diretores. Atualmente, a empresa usa o software específico para calcular o preço de projeto utilizando diferentes variáveis sendo umas delas o histórico de preços cobrados pela empresa por tipo de projeto. As visitas às obras não estão incorporadas no valor cobrado. A empresa realiza visitas às obras sempre que o cliente solicita.

A implantação do SGQ acarretou grandes modificações na área de recursos humanos, principalmente no que se refere ao treinamento. Apesar de o sistema não ter causado grandes modificações nas tarefas diárias, ele ajudou a registrar o modo de trabalho criando-se um padrão para toda a empresa. O treinamento dos novos funcionários passou a ser mais fácil, pois todos os processos da empresa estão escritos, mostrando exatamente quais tarefas devem ser realizadas e quais resultados são esperados de cada atividade.

"A gente tem agora tudo redigido, todas as atividades que devem ser feitas. Esses departamentos têm os critérios de avaliação, como registrar, como entregar as coisas para o cliente, coisa que antigamente estava na cabeça de cada coordenador. A pessoa nova que entrava não sabia, ficava muito na mão do coordenador. Agora o conhecimento está mais disseminado, justamente porque está escrito e é público para todos."

(Representante da Direção entrevista realizada em 04/2006)

A empresa também destaca que com as constantes mudanças de softwares, o estabelecimento de um plano de treinamento tem sido importante para capacitar seus funcionários. Além disso, com a implantação do SGQ os funcionários se tornaram mais conscientes de sua importância para empresa e para o bom andamento dos projetos. 
"A forma como eles enxergam suas responsabilidades perante aos clientes internos e externos. Então, isso sim eu acho que a ISO trouxe de melhoria aqui para a gente. Porque a gente tem uma matriz de responsabilidades, a quem eles têm que se reportar, a gente tem um organograma divulgado para todos. Isso antes até existia, mas não era divulgado. Essa é a importância que eu vi em relação aos recursos humanos, é a seriedade com que os funcionários percebem o seu trabalho."

(Representante da Direção entrevista realizada em 04/2006)

Por exigência da norma ISO 9001, a empresa criou um manual de cargos, mudando um pouco a seleção de novos funcionários. Antigamente, não havia um processo de seleção definido e os novos funcionários eram contratados por indicação de funcionários já incorporados ao quadro. Atualmente, apesar de muitos funcionários chegarem à empresa através de indicações, são exigidas habilidades mínimas para o cargo pretendido e normalmente há aplicação de um teste.

A empresa B trabalha com projetistas parceiros que a auxiliam no desenvolvimento de algumas etapas do projeto arquitetônico. Em atendimento à norma ISO 9001/2000 que exige o estabelecimento de critérios de seleção e avaliação desses projetistas, a criou-se um cadastro de projetistas que possui critérios tanto para a aceitação de um novo profissional como para sua permanência no cadastro.

Para a empresa outro grande benefício da certificação está ligado ao seu sistema de informação. Antes, a organização dos registros era feita de forma informal na empresa. Com o SGQ, criou-se um padrão de registro, selecionando-se quais informações deveriam ser registradas e como deveriam ser armazenadas, implicando diretamente a melhor organização da empresa. A criação de registros também é fundamental para que a empresa possa realizar a análise crítica, pois é através deles que podem ser verificados os problemas ocorridos durante o desenvolvimento dos projetos e se propor ações de para corrigi-los e evita-los em projetos futuros.

Outra mudança importante foi a melhoria na comunicação entre a empresa e os parceiros. Desde a implantação do SGQ eles iniciaram a utilização de site colaborativo para auxiliar na comunicação com os projetistas das especialidades de forma que estes pudessem ter acesso a todas as plantas de arquitetura através do site e fossem informados sobre as novas versões, evitando o uso de plantas e informações obsoletas.

Como a empresa também faz a coordenação e compatibilização dos demais projetos, outra ferramenta que vem ajudando a comunicação com os projetistas é a criação de uma lista de verificação para cada especialidade. Essas listas foram criadas para ajudar a gerenciar a interface entre todos os projetos e nelas são listadas todas as informações necessárias ao projeto. Elas servem como um roteiro, sendo utilizadas pela empresa na conferência dos dados dos projetos.

A empresa mantém uma biblioteca digital de detalhes que inclui aqueles de maior incidência nos projetos. Essa biblioteca sempre existiu, mesmo antes do SGQ. Ela está sempre em expansão, pois novos detalhes são constantemente incorporados. 
Com relação à comunicação da empresa com seu contratante, a prática adotada era de, a cada etapa entregue, solicitar a realização de avaliação de desempenho (qualidade, prazo, cumprimento de exigências, entre outros). Atualmente, além dessa prática, a empresa criou um canal novo de comunicação com o cliente - a medição e monitoramento satisfação dos clientes. Para o seu cumprimento, a empresa envia fichas de avaliação ao final da obra, para que o cliente contratante avalie a empresa e o projeto fornecido. Essa nova prática tem se mostrado eficaz pois traz um feedback dos clientes sobre os serviços e produtos da empresa, inclusive provocando modificações / revisões nos procedimentos. A empresa também tem feito pesquisa de satisfação com os clientes finais (usuários dos edifícios), mas o retorno dessa pesquisa é muito pequeno, não tendo provocado, até o término desta pesquisa nenhuma mudança no sistema da qualidade implantado.

A empresa não tinha nenhum indicador de produção anterior à implantação do SGQ; todos os indicadores foram criados depois da implantação o que impossibilita a análise sobre o aumento da produtividade.

Na opinião do entrevistado, não existe nenhuma dificuldade na manutenção do SGQ, bastando que a equipe disponibilizasse parte do seu tempo na realização de atividades de monitoramento e medição.

Apesar da certificação pela norma ISO 9001:200 não ter trazido nenhum fator de diferenciação no mercado, a empresa B pretende manter a certificação pois ela estabelece a obrigatoriedade da manutenção do sistema.

\subsection{Resultados da Empresa C}

A empresa $C$ enxergou na implantação de um sistema de gestão da qualidade, a oportunidade de sedimentar as rotinas já aplicadas no escritório como, por exemplo, as formas de acompanhamento do produto e de controle das informações recebidas e repassadas em cada projeto. Além disso, a Certificação ISO 9001:2000 seria, na opinião do entrevistado, uma forma da empresa se destacar perante a concorrência (diferencial de mercado).

Para auxiliar no processo de implantação do SGQ, a empresa contratou uma consultoria especializada. A implantação durou cerca de um ano e meio, e em 2005 a empresa foi certificada.

A principal dificuldade durante a implantação do SGQ foi assimilar a mudança de cultura, pois a empresa não tinha uma rotina formal estabelecida.

Assim como as empresas anteriormente descritas, a empresa $C$ não considera que o SGQ tenha influência sobre o seu processo criativo; para ela o sistema influencia na produção do projeto. Como principais mudanças ocorridas na empresa, destacamse a melhoria do sistema de informações e o maior controle de produção.

“(...) eu acho que na própria organização do escritório, na maneira como os projetos saem. Quer dizer, a ISO não te dá qualidade de projeto, ela te dá qualidade de produção do projeto executivo. Te dá qualidade de ter um projeto que saia do escritório com o mínimo de erros possíveis o que é, inclusive, uma de nossas metas. Então, o sistema de gestão da qualidade azeita essa estrutura Evidentemente 
que você não aprende a projetar com sistema de gestão da qualidade, mas você põe 'ordem na casa'. Para nós foi muito interessante."

(Diretor da empresa C entrevista realizada em 04/2006)

A exemplo das empresas anteriormente descritas, antes da implantação do SGQ esta empresa não tinha uma estrutura organizacional formalmente estabelecida. Após a implantação, o organograma da empresa foi formalizado e divulgado para seus funcionários.

Antes da implantação do SGQ a empresa também não realizava seu planejamento estratégico que passou a ser realizado, com o estabelecimento de metas de médio e longo prazo. Para verificar o cumprimento dessas metas, a empresa estabeleceu mecanismos visando ao monitoramento da produção e à coleta de dados sobre o andamento dos projetos, com informações tais como: número de estudos feitos no escritório, número de estudos aprovados e número de horas dispendidas em cada projeto.

Com relação aos aspectos relacionados ao marketing, a prospecção de novos clientes sempre foi feita pelos arquitetos titulares que acreditam ser a certificação pela norma ISO 9001/2000 um fator de diferenciação no mercado para conseguir novos clientes.

Sobre os aspectos ligados aos recursos humanos, antes da implantação, a empresa não fazia ou incentivava o treinamento dos funcionários e não tinha procedimentos estabelecidos para seleção e contratação de pessoas. Devido à exigência da norma, a empresa passou a planejar o treinamento de seus funcionários e criou critérios para seleção de novos funcionários.

Não houve modificação na forma de calcular o preço cobrado pelos projetos após a implantação do SGQ. A empresa calcula o preço de projeto com base na tabela do órgão de classe e no preço médio cobrado no mercado. Apesar da empresa medir o número de horas trabalhadas em cada projeto, esse dado não é utilizado como base para estabelecer o preço.

A mudança mais importante ocorrida com a implantação do SGQ aconteceu no sistema de informação. Passou-se a ter maior controle sobre as informações dos projetos, pois se criou uma sistemática de armazenamento. Antes, a organização dos registros era feita informalmente. Com o SGQ, criou-se uma norma para identificação, arquivamento e controle de alterações de projeto. Além disso, estabeleceu-se um processo de cópias periódicas. Essas ações implicaram diretamente na melhor organização da empresa. A empresa há pouco tempo começou a desenvolver uma biblioteca digital com seus detalhes padronizados. Com relação ao uso de ambientes colaborativos, a empresa os vem utilizando quando o cliente contratante também os utiliza.

A avaliação do cliente contratante (incorporadoras e construtoras) passou a ser feita em decorrência da implantação do SGQ. Essas informações são utilizadas para re-alimentar o projeto. Mas a empresa ainda não faz pesquisa de satisfação com os usuários finais. 
Para a empresa C, a principal dificuldade de manutenção do SGQ é manter a equipe motivada para continuar fazendo o sistema "rodar". Ela pretende renovar sua certificação.

\subsection{Resultados da Empresa D}

No início da sua atuação, a empresa D realizava projetos de vedações. Desde aquela época, a empresa já desenvolvia procedimentos escritos que auxiliavam no treinamento da sua equipe. A partir de 1997, para melhor organizar suas práticas, os diretores resolveram participar de cursos sobre as normas ISO e começaram a aplicá-las na sua empresa, criando paulatinamente a documentação exigida.

Em 1999, um dos seus clientes, que estava se certificando pela norma, solicitou que seus fornecedores também o fizessem, informando que ele pretendia contratar somente empresas que também estivessem certificadas. Como a empresa D já tinha começado a implantar por conta própria a norma ISO 9001 / 1994, ela decidiu dar continuidade ao processo com auxílio de um consultor e, em 2001, a empresa foi certificada pela primeira vez ainda pela versão antiga da norma.

$\mathrm{Na}$ fase de implantação, a principal dificuldade foi administrar o tempo dos funcionários no desenvolvimento de suas tarefas do dia-a-dia e na produção dos documentos necessários para o SGQ. A empresa D destaca que todo o sistema foi construído com ajuda dos funcionários, não foi um processo imposto, o que considera como um ponto positivo e fundamental para que o sistema desse certo e funcionasse.

A empresa considera que não tem como avaliar se o processo criativo é influenciado pela implantação do SGQ, uma vez que não participa da fase de concepção dos projetos, assumindo-os somente após a aprovação do projeto legal. Para o entrevistado com a implantação do SGQ houve melhoria do sistema de informações, do treinamento de funcionários e melhoria do produto entregue ao cliente.

A estrutura organizacional da empresa também não estava formalmente estabelecida antes da implantação do SGQ. Com a implantação, seu organograma foi estabelecido e divulgado entre os colaboradores.

A empresa D sempre fez um planejamento de seus custos, porém nunca planejou formalmente outros aspectos da empresa (planejamento estratégico). Com a implantação do SGQ, ela passou a estabelecer os objetivos da qualidade, definindo formalmente suas metas a médio e longo prazo. Foram estabelecidas metas em relação à: satisfação dos clientes, treinamento dos funcionários, melhoria contínua dos serviços com a incorporação de novas tecnologias, manutenção e conquista de novos clientes. Entretanto, em relação a este último objetivo, cabe destacar que a empresa não adotou nenhuma ação de marketing específica para esse fim. A empresa considera que divulgação do seu trabalho se dá por meio de divulgação "boca-a-boca".

"Na verdade, a divulgação do nosso trabalho, a maior divulgação do nosso trabalho é a própria fidelização do nosso cliente e a eficiência do nosso trabalho. Então, nosso trabalho tem qualidade, 
ou seja, nós atendemos a satisfação do cliente. A gente vai fazer com que esse cliente retorne para efetuar novos serviços com a gente. Esse cliente, ele mesmo se encarrega de fazer uma propaganda boca-a-boca".

(Diretora da empresa D entrevista realizada em 10/2006)

O calculo do preço do projeto varia conforme o escopo de serviço. Nos projetos de vedações, a empresa afirma que já existe um preço estabelecido pelo mercado e a empresa o segue. Para o desenvolvimento e coordenação de projetos, a empresa mantém um histórico com seus gastos diretos e indiretos. Nestes casos o preço do projeto é baseado nesse histórico e também no preço estabelecido pelo mercado. Quanto à visita a obra, quando a empresa é contratada, ela já inclui em seu escopo um número limitado de visitas, e, quando esse número é ultrapassado, passa-se a cobrar pela hora técnica.

De acordo com a visão da entrevistada, a certificação não tem sido um fator de diferenciação no mercado para conseguir novos clientes e manter clientes e, além disso, não é um item levado em conta quando o cliente quer contratar uma empresa de projeto.

A empresa considera que o SGQ teve grande impacto nos aspectos ligados aos recursos humanos. Com o SGQ a empresa passou a registrar sua forma de trabalho, o que foi essencial para auxiliar no treinamento dos novos funcionários. Apesar de a empresa já ter processos de trabalho escritos antes da certificação, esta trouxe melhorias nesse campo, como o planejamento de treinamento. Esse item é importante, pois, conforme há a compra de novos softwares, se estabelece treinamentos para capacitar seus funcionários.

Atualmente, o planejamento de treinamento abrange toda equipe, inclusive seus diretores. Na área técnica, os desenhistas recebem treinamento para sua função e tem a possibilidade de receber treinamento para alcançar funções de maior responsabilidade - como a de supervisor ou coordenador de projetos.

Anteriormente à implantação do SGQ, a empresa não tinha regras estabelecidas para contratação de funcionários. Como parte de uma exigência da norma, a empresa criou o manual de cargos, onde as competências e habilidades mínimas são descritas. Porém, esse manual passou a ser mais do que um guia de seleção de novos funcionários Tornou-se, no momento da implantação do sistema, um guia para o treinamento interno dos funcionários já contratados.

Após a implantação do SGQ, a empresa D considera que o sistema de informação melhorou muito com a criação de registros formais e de padrões para armazenamento destes, melhorando a rastreabilidade dos documentos. Como exemplos, a empresa cita que a comunicação com o cliente melhorou devido à criação de documentos, como o roteiro para guiar a coleta de dados com o cliente (dados de entrada), o que ocasionou a diminuição de reclamações do cliente com o produto entregue. Além deste cabe citar o estabelecimento de um relatório mensal de acompanhamento de projetos, que informa ao cliente o andamento do mesmo.

Sobre a relação arquiteto-coordenador x projetistas de especialidades, a empresa cita a criação de registros simples como relatórios de compatibilização, atas de 
reunião e cronograma de projetos tem ajudado na comunicação entre os projetistas. Nesses relatórios de compatibilização (chamados de também de pré-atas) são listados os problemas dos projetos que deverão ser levados a reuniões com os projetistas, servindo como um guia para discussões. Nessas reuniões, todas as soluções e decisões tomadas são descritas ao lado de cada problema, gerando uma ata de reunião que é distribuída para toda a equipe de projeto. $\mathrm{O}$ estabelecimento de um cronograma de projeto também tem ajudado no cumprimento dos prazos de entrega de projeto.

Para a empresa D, o uso de sites colaborativos já é habitual e tem facilitado o gerenciamento de projetos. Essa ferramenta é utilizada quando seus clientes (incorporadoras ou construtoras) já utilizam esse tipo de ferramenta e solicitam aos seus fornecedores que o utilizem. Quando o contratante não fornece essa ferramenta, a troca de informações é feita por e-mail.

A empresa D também destaca a importância de ferramentas de retroalimentação do SGQ, que ajudam a sanar problemas ocorridos. Foram criados: um formulário específico para registrar visita a obras, onde são registrados todos os pontos positivos e negativos do projeto em relação à obra; e um questionário de avaliação de satisfação do cliente (incorporadoras e construtoras ${ }^{1}$ ). As informações desses documentos são utilizadas nas reuniões internas de análise crítica, e servem de base para retroalimentação dos projetos e do SGQ. Em função dessas informações, alguns procedimentos podem ser alterados em busca da melhoria do sistema.

Para a empresa D, a principal dificuldade de manutenção do SGQ é o custo. Para essa empresa, esse custo é muito alto e torna-se quase proibitivo para uma empresa de seu porte, motivo pelo qual, quando o certificado expirar, a empresa não terá condições de se re-certificar. Mesmo assim, continuará usando o SGQ, pois entende que este é essencial para o bom funcionamento da mesma.

\section{CONSIDERAÇÕES SOBRE OS RESULTADOS OBTIDOS}

$\mathrm{Na}$ pesquisa, procurou-se obter dados sobre aspectos gerais do SGQ - como motivação para implantação, principais dificuldades de manutenção e mudanças significativas - e sobre aspectos mais específicos, como o impacto do SGQ na estrutura organizacional, planejamento estratégico, marketing, gestão financeira, recursos humanos e sistema de informação.

Duas empresas citaram como principais motivos para implantação do SGQ a solicitação de um cliente que também estava se certificando e o desejo de sedimentar rotinas de trabalho. Uma empresa citou como principal motivação o marketing e outra o desejo de modernização da empresa.

Todas as empresas destacam que o SGQ trouxe melhorias no sistema de informação. Para todas as empresas entrevistadas o sistema trouxe um maior controle sobre a informação recebida e gerada, através da criação de registros e procedimento de armazenamento. $\mathrm{O}$ segundo aspecto mais citado foi a melhoria do treinamento nas empresas, no que diz respeito tanto à criação de procedimentos (descrição das atividades) que auxiliam no treinamento dos funcionários, quando à maior preocupação em manter a equipe capacitada. $\mathrm{O}$ terceiro aspecto mais citado

\footnotetext{
${ }^{1}$ Não fazem pesquisa de satisfação com os usuários finais (moradores)
} 
foi o maior controle sobre o processo de produção do projeto. É importante lembrar que esse aspecto está diretamente ligado à melhoria do sistema de informações, pois seu controle só é possível através da criação de ferramentas que auxiliam no registro e armazenamento de informações ${ }^{2}$. (Gráfico 2)

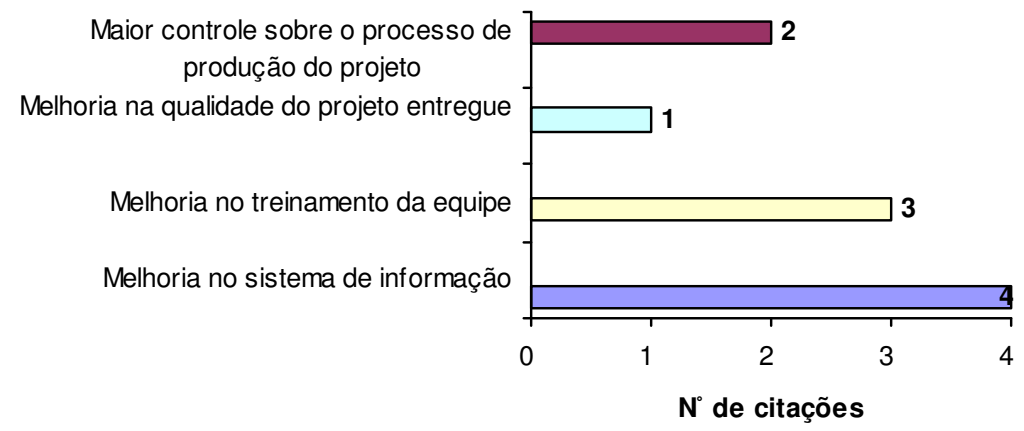

\section{Gráfico 2 - Quais as mudanças significativas na empresa com a implementação do} Sistema de Gestão da Qualidade?

Todas as empresas disseram que houve dificuldades na implantação do SGQ. Os motivos mais citados foram: conciliar o desenvolvimento das tarefas do dia-a-dia de cada funcionário com a produção dos documentos necessários para o SGQ; e a mudança da cultura da empresa.

Quanto a dificuldades de manutenção, apenas dois aspectos foram citados: a dificuldade financeira foi citada por duas empresas, pois os custos somados da certificação, da auditoria, da consultoria e das horas de trabalho dos funcionários dedicados ao SGQ são considerados caros para micro e pequenas empresas. Uma empresa citou a dificuldade em manter a equipe motivada para exercer as atividades exigidas pelo sistema. Apenas para uma das empresas não há dificuldades de manutenção.

Quanto à estrutura organizacional, verificou-se que antes da implantação do SGQ, nenhuma das empresas tinha uma estrutura formalizada e estabelecida. Após a implantação, maioria delas passou a representar no papel a estrutura informal já existente, porém que não era anteriormente divulgada para seus funcionários. Esse fato se deve a influencia indireta do requisito da norma ISO 9001:2000 referente aos requisitos gerais do SGQ, pelos quais as empresas devem de identificar todos os processos (técnicos, gerenciais e operacionais), estabelecendo responsabilidades e canais de comunicação.

Quanto ao planejamento estratégico, nenhuma empresa o realiza na integra. Antes da implantação do SGQ, apenas a empresa D realizava um planejamento sobre os custos da empresa. Depois da implantação do SGQ, todas as empresas passaram a realizar um plano de metas cujos objetivos mais comuns são: capacitar seus funcionários, pesquisar os níveis de satisfação dos clientes e cumprimento de

2 Como as perguntas aplicadas foram abertas, ou seja não tinham respostas pré-definidas, cada empresa pode respondê-las livremente dando uma ou mais respostas. Por esse motivo, os números de respostas representadas nos gráficos podem somar mais de 4 . 
prazos. Essa mudança é influenciada indiretamente pelo item da norma ISO 9001:2000 referente ao planejamento do SGQ. Segundo esse item, a empresa deve estabelecer objetivos mensuráveis sobre o funcionamento do SGQ.

Quanto às estratégias de marketing das empresas, verificou-se que a implantação do SGQ não trouxe nenhuma modificação quanto à posição das empresas nesse aspecto. Com exceção da empresa A, que estabeleceu no seu plano de metas o objetivo de aumentar a evidencia da empresa nas propagandas em mídia, nenhuma das demais empresas, após implantação do sistema da qualidade, alterou sua maneira de promoção e de prospecção de novos clientes.

É importante lembrar que nenhum item específico da norma ISO 9001:2000 estabelece ferramentas com o propósito de detectar oportunidades de mercado, despertar interesse desse mercado e gerar relações comerciais. Entretanto, alguns aspectos ligados a um sistema de marketing podem ser considerados no plano de metas do escritório (como fez a empresa A), estando diretamente relacionados com os objetivos da qualidade. Entre as metas, pode-se citar a busca de novos clientes e a promoção da empresa. Cabe destacar que o mero estabelecimento de metas não configura uma estratégia de marketing.

A Pesquisa de Satisfação com Clientes não era realizada por nenhuma das empresas antes do SGQ, como essa é uma exigência da norma todas passaram a realizá-la. De acordo com Padilha (2001), essa pesquisa pode ser considerada uma ferramenta de marketing, pois mostra que a empresa se importa com a opinião do cliente e tem interesse em incorporar suas opiniões no serviço oferecido.

Quanto à gestão financeira, a implantação do SGQ pouco influenciou a maneira como as empresas calculam os preços de projetos. Esse fato pode se justificar pela norma não possuir nenhum requisito que oriente as empresas sobre a gestão financeira. Porém, pode-se destacar que, ao se identificar todas as etapas necessárias para elaboração do projeto, essa divisão pode auxiliar: na definição do escopo e do conteúdo de cada projeto; na definição de um cronograma e de estimativa de custo de cada etapa; na padronização dos procedimentos; e na definição de critérios para a remuneração de serviços. As referências mais utilizadas para o cálculo são o histórico de preços de projetos anteriores e o preço de mercado.

Quanto aos recursos humanos, de acordo com o gráfico 2, três das quatro empresas destacaram que o SGQ contribuiu para sua melhoria, principalmente no treinamento da sua equipe. Antes da implantação do SGQ, nenhuma das empresas pesquisadas fazia um planejamento formal de treinamento de seus funcionários. Nota-se que, com a implementação do sistema, o treinamento de novos funcionários passou a ser formal e mais estruturado, pois anteriormente as empresas não tinham suas rotinas de trabalho redigidas e divulgadas e as responsabilidades não eram bem definidas. Essas informações faziam parte somente do conhecimento dos diretores ou coordenadores das empresas.

Antes do SGQ, nenhuma das empresas tinha um critério para seleção de funcionários, que geralmente era feita com base em indicações. Atualmente, todos os escritórios criaram Manuais de Cargos, nos quais indicam habilidades mínimas exigidas para cada função da empresa e que servem de baliza para contratação de novos funcionários. 
As mudanças descritas nos dois parágrafos anteriores são uma influencia direta dos itens relacionados à gestão de recursos. Esses itens tratam da determinação de competências necessárias para cada função e exigem o estabelecimento formal do perfil de competências para cada função e, conseqüentemente, o estabelecimento de requisitos formais para a admissão de pessoal. Também tratam do planejamento de treinamento para os funcionários, de forma a incentivar a constante capacitação do pessoal.

As empresas que usam o serviço de projetistas externos à empresa para auxiliar no desenvolvimento de etapas do projeto de arquitetura, passaram também a selecioná-los e avaliá-los, mantendo um cadastro de fornecedores. Assim, ao escolher um projetista, a empresa passa a ter uma fonte de consulta permanente e formal sobre a capacidade de cada profissional para atender suas necessidades. Essa mudança é uma influencia direta da norma através do item referente ao controle do processo de aquisição.

Conforme demonstrado no gráfico 2, o sistema de informação foi apontado como o subsistema mais afetado das empresas. Todas citaram que não tinham registros formais de projeto, padrões para armazenamento e para recuperação de informações. Com a implantação do SGQ, as empresas criaram padrões de criação e armazenamento de arquivos eletrônicos; de apresentação de todos documentos gerados pela empresa; de circulação de documentos; de elaboração de cópias de segurança; e de armazenamento de documentos físicos. O estabelecimento de um fluxo de desenvolvimento do projeto auxiliou no estabelecimento do fluxo de informações, possibilitando o maior controle sobre o processo de produção do projeto.

Além disso, a implantação do SGQ possibilitou formalizar a coleta de dados e o tratamento das informações e, como conseqüência, houve uma melhoria no fluxo de informações, particularmente no que diz respeito ao compartilhamento de informações entre os agentes envolvidos no processo de projeto.

As modificações observadas no sistema de informação são influencia direta da ISO 9001:2000, já que vários dos requisitos da norma se relacionam organização do sistema de gestão de informação da empresa.

\section{CONSIDERAÇÕES FINAIS}

As pesquisas na área da gestão do processo de projeto ganharam novo impulso, principalmente, a partir da segunda metade da década de 90. A certificação dos escritórios de arquitetura foi impulsionada em grande parte pela certificação das construtoras, motivadas pelo PBQP-H. Entretanto, esta pesquisa, realizada em março de 2006, demonstrou que, no Brasil, o número de escritórios de arquitetura que possue seus sistemas de gestão certificados pela norma ISO 9001:2000 ainda é reduzido.

Na maioria das empresas estudadas a certificação pela norma não é considerada um fator de diferenciação no mercado e seu alto custo financeiro é um empecilho para a sua manutenção. Apesar disso, essas empresas afirmam que manteriam o sistema de gestão da qualidade implantado mesmo se não tivessem condições de renovar a certificação, pois todas o consideram uma ferramenta importante para a organização do processo de produção. 
Logo, é importante destacar que o principal benefício da implantação do SGQ (certificado ou não) é criação de um sistema de gestão que auxilie na administração e organização dos processos da empresa, e que a certificação do SGQ se torna importante quando a contratação da empresa está vinculada à obtenção desta.

A respeito da influencia da norma nos aspectos administrativos das empresas de projeto, constatou-se que as maiores mudanças geradas pela norma ocorreram no sistema de informações e na gestão dos recursos humanos das empresas. É importante notar também que, na percepção das empresas, a maior contribuição da norma se refere à melhoria na gestão da informação e na comunicação entre os envolvidos no projeto (aspectos ligados ao sistema de informações).

Isso se deve ao fato de que grande parte dos requisitos da norma estar relacionada à organização do sistema de gestão de informação. A norma orienta acerca de procedimentos (rotinas de trabalho) que devem ser identificados e planejados, visando ao controle das atividades relacionadas com o desenvolvimento de projeto. Além disso, ela é enfática sobre a importância da documentação e da padronização dessas atividades.

Assim, as modificações ocorridas no sistema de informação das empresas colaboraram para melhoria na gestão do processo do projeto, através da organização do processo de produção (melhor gerenciamento das atividades e tarefas necessárias à realização do projeto), gerando melhorias consideráveis no que diz respeito à produção de documentos que representam o projeto. Deste modo, entende-se que um dos resultados indiretos da implantação da norma poderá ser a melhoria da qualidade das soluções propostas uma vez que o processo como um todo passa a ser melhor gerenciado.

Através dos dados obtidos, ainda é importante questionar se as mudanças observadas como conseqüência da implantação do SGQ nas empresas de arquitetura são específicos desse tipo de empresa ou se ocorrem em qualquer empresa que busque a certificação. Essa questão poderia ser respondida através do desenvolvimento de um estudo comparativo entre empresas de vários setores, a fim de identificar se os impactos nos aspectos gerenciais variam de acordo com o tipo e tamanho de empresa e de acordo com o setor do mercado.

Ao término desta pesquisa, em outubro de 2006, identificou-se um crescimento pequeno no número de escritórios de arquitetura certificados no país. Logo, entende-se que com as novas experiências em certificação, outras questões serão identificadas. Por essa razão, cabe destacar que esta pesquisa não teve a intenção de esgotar a reflexão sobre este assunto, mas sim trazer mais uma contribuição às discussões na área.

\section{REFERÊNCIAS BIBLIOGRÁFICAS}

CTE - Centro de Tecnologia de Edificações, NGI - Núcleo de Gestão e Inovação. Programa de gestão da qualidade no desenvolvimento de projeto na construção civil. Apostila organizada para o programa, 6 módulos, 2001.

FERREIRA, C. Contribuição aos Estudos para a Implantação de um Sistema de Gestão da Qualidade em escritórios de Arquitetura.2006. $122 \mathrm{f}$. Dissertação (Mestrado em Arquitetura) - PROARQ/FAU/UFRJ, Rio de Janeiro, 2006. 
GRAY, C. e AL-BIZRI, S.. Modelling for planning building design - a critique of available approaches. In: The international construction research conference of the Royal Institution of Chartered Surveyors, COBRA, 2004.

KOTLER, P.; BLOOM, P. N. Marketing para serviços profissionais. São Paulo: Atlas, 1988.

KOTLER, P. Marketing. Edição Compacta. São Paulo: Atlas, 1980.

MAXIMINIANO, A. C. A. Introdução a administração. 4a edição revista e ampliada. São Paulo: Atlas, 1995.

NASCIMENTO, L. A. N.; SANTOS, E. T. A industria da construção na era da informação. Brasil - Porto Alegre, RS. 2003. Ambiente Construído, jan./mar v. 3, n. 1 p. 69-81.

OLIVEIRA, D. P. R. Sistemas, organização e métodos: uma abordagem gerencial. 5 ed. São Paulo: Atlas, 1994.

OLIVEIRA, Otávio José de. Modelo para gestão para pequenas empresas de projeto de edifícios. 2005. 262 f. Tese (Doutorado em Engenharia Civil) POLI/USP, São Paulo, 2005.

PADILHA, Ênio. Marketing para engenharia, arquitetura e agronomia. 6 ed. Santa Catarina: Palloti, 2006.

PINTO, R. L.. Evolução da estrutura organizacional ao longo do ciclo de vida do projeto: um estudo de caso. 2002. 172 f. Dissertação (Mestrado em administração) - Universidade de São Paulo, São Paulo, 2002.

PSQ - PROGRAMA setorial da qualidade. PSQ - Setor de projetos. São Paulo: Companhia de Desenvolvimento Habitacional e Urbano do Estado de São Paulo (CDHU), 1997.

SALGADO, M. S. Apostila para a disciplina - Gestão do Processo de Projeto na Construção do Edifício. Rio de janeiro: PROARQ/ FAU/ UFRJ, 2006.

SALGADO, M. S. Gestão do Processo do Projeto do Edifício: uma discussão. Cadernos do PROARQ, v. 9, p. 29-42, 2005.

SEBRAE. Disponível em: <www.sebrae.com.br>. Acessado em: 19 de julho de 2006.

SCHEER, S.; CARARO, J. F. J. A formação de preço em escritórios de arquitetura com suporte em sistemas de informação. In: Encontro Nacional de Tecnologia do Ambiente Construído (ENTAC), 10., São Paulo. Anais. São Paulo: ENTAC, 2004. 1 CD-ROM.

SOUZA, R.; (colaboradores Josaphat Baía, Hisae Gunji). Sistema de Gestão para empresas de incorporação imobiliária. São Paulo: O Nome da Rosa, 2004.

YIN, R. K. Estudo de caso: planejamento e método. 3 ed. São Paulo: Bookman, 2005. 